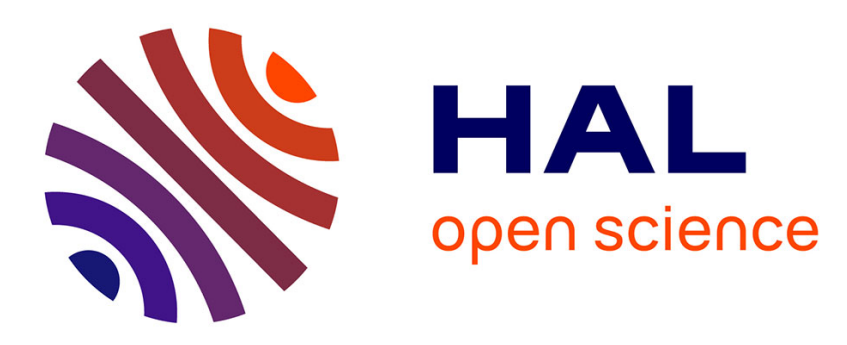

\title{
Ag doped silicon nitride nanocomposites for embedded plasmonics
}

\author{
Maxime Bayle, Caroline Bonafos, Patrizio Benzo, Gérard Benassayag, \\ Béatrice Pécassou, L. Khomenkova, F. Gourbilleau, Robert Carles
}

\section{- To cite this version:}

Maxime Bayle, Caroline Bonafos, Patrizio Benzo, Gérard Benassayag, Béatrice Pécassou, et al.. Ag doped silicon nitride nanocomposites for embedded plasmonics. Applied Physics Letters, 2015, 107 (10), 10.1063/1.4930940 . hal-01241265

\section{HAL Id: hal-01241265 \\ https://hal.science/hal-01241265}

Submitted on 10 Dec 2015

HAL is a multi-disciplinary open access archive for the deposit and dissemination of scientific research documents, whether they are published or not. The documents may come from teaching and research institutions in France or abroad, or from public or private research centers.
L'archive ouverte pluridisciplinaire HAL, est destinée au dépôt et à la diffusion de documents scientifiques de niveau recherche, publiés ou non, émanant des établissements d'enseignement et de recherche français ou étrangers, des laboratoires publics ou privés. 


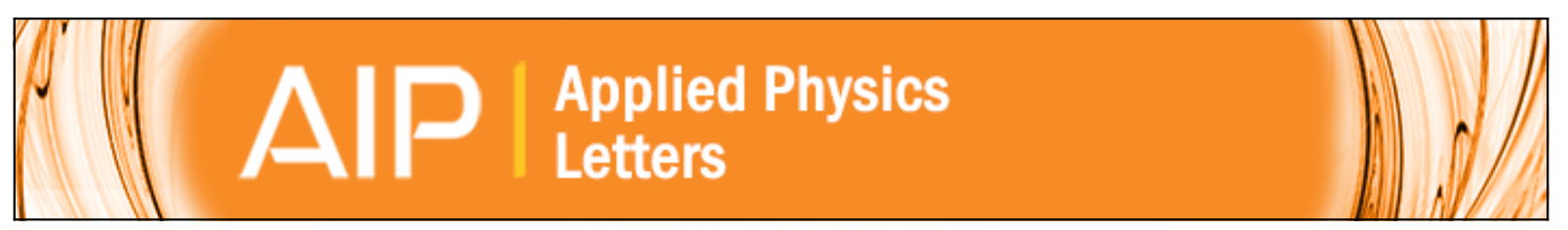

\section{Ag doped silicon nitride nanocomposites for embedded plasmonics}

M. Bayle, C. Bonafos, P. Benzo, G. Benassayag, B. Pécassou, L. Khomenkova, F. Gourbilleau, and R. Carles

Citation: Applied Physics Letters 107, 101907 (2015); doi: 10.1063/1.4930940

View online: http://dx.doi.org/10.1063/1.4930940

View Table of Contents: http://scitation.aip.org/content/aip/journal/apl/107/10?ver=pdfcov

Published by the AIP Publishing

\section{Articles you may be interested in}

Metal-polymer nanocomposite with stable plasmonic tuning under cyclic strain conditions

Appl. Phys. Lett. 107, 073106 (2015); 10.1063/1.4928725

Localized surface plasmon resonance in SnS:Ag nano-composite films

J. Appl. Phys. 115, 204512 (2014); 10.1063/1.4880317

Strong coupling between Rhodamine $6 \mathrm{G}$ and localized surface plasmon resonance of immobile Ag nanoclusters fabricated by direct current sputtering

Appl. Phys. Lett. 102, 143112 (2013); 10.1063/1.4801633

Transparent SiO2-Ag core-satellite nanoparticle assembled layer for plasmonic-based chemical sensors Appl. Phys. Lett. 100, 223101 (2012); 10.1063/1.4722583

In situ optical microspectroscopy approach for the study of metal transport in dielectrics via temperature- and time-dependent plasmonics: Ag nanoparticles in SiO2 films

J. Chem. Phys. 134, 054707 (2011); 10.1063/1.3537736

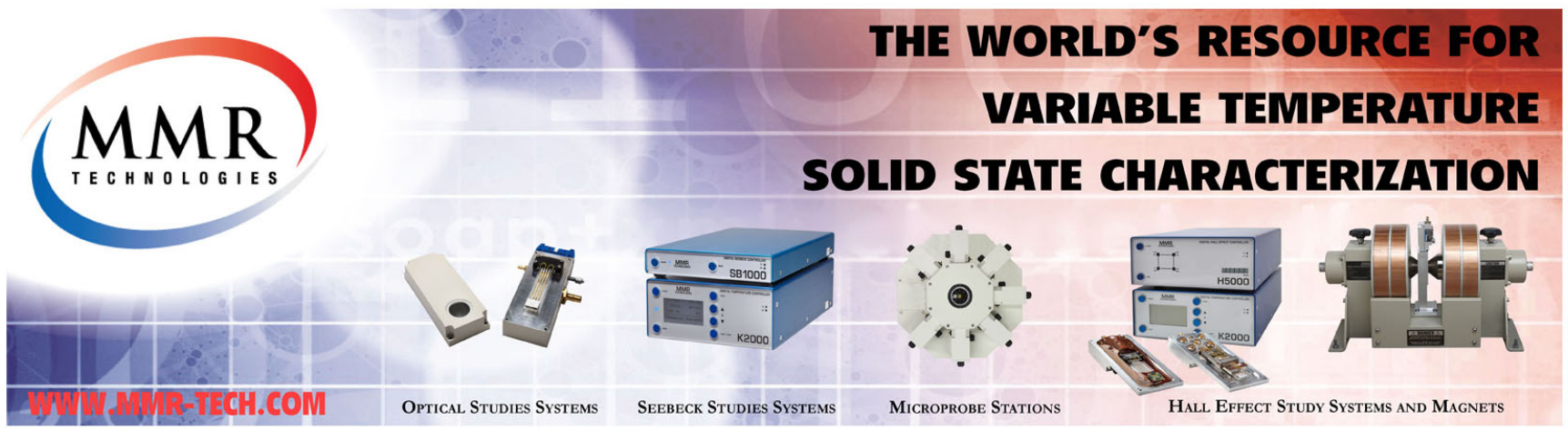




\title{
Ag doped silicon nitride nanocomposites for embedded plasmonics
}

\author{
M. Bayle, ${ }^{1}$ C. Bonafos, ${ }^{1, a)}$ P. Benzo, ${ }^{1}$ G. Benassayag, ${ }^{1}$ B. Pécassou, ${ }^{1}$ L. Khomenkova, ${ }^{2, b)}$ \\ F. Gourbilleau, ${ }^{2}$ and R. Carles ${ }^{1}$ \\ ${ }^{1}$ CEMES-CNRS and Université de Toulouse, 29 rue J. Marvig, 31055 Toulouse, Cedex 04, France \\ ${ }^{2}$ CIMAP, CNRS/CEA/ENSICAEN/UCBN, 6 Boulevard Maréchal Juin, 14050 Caen, Cedex 4, France
}

(Received 9 July 2015; accepted 2 September 2015; published online 11 September 2015)

\begin{abstract}
The localized surface plasmon-polariton resonance (LSPR) of noble metal nanoparticles (NPs) is widely exploited for enhanced optical spectroscopies of molecules, nonlinear optics, photothermal therapy, photovoltaics, or more recently in plasmoelectronics and photocatalysis. The LSPR frequency depends not only of the noble metal NP material, shape, and size but also of its environment, i.e., of the embedding matrix. In this paper, Ag-NPs have been fabricated by low energy ion beam synthesis in silicon nitride $\left(\mathrm{SiN}_{\mathrm{x}}\right)$ matrices. By coupling the high refractive index of $\mathrm{SiN}_{\mathrm{x}}$ to the relevant choice of dielectric thickness in a $\mathrm{SiN}_{\mathrm{x}} / \mathrm{Si}$ bilayer for an optimum antireflective effect, a very sharp plasmonic optical interference is obtained in mid-range of the visible spectrum $(2.6 \mathrm{eV})$. The diffusion barrier property of the host $\mathrm{SiN}_{\mathrm{x}}$ matrix allows for the introduction of a high amount of $\mathrm{Ag}$ and the formation of a high density of Ag-NPs that nucleate during the implantation process. Under specific implantation conditions, in-plane self-organization effects are obtained in this matrix that could be the result of a metastable coarsening regime. (C) 2015 AIP Publishing LLC. [http://dx.doi.org/10.1063/1.4930940]
\end{abstract}

The localized surface plasmon-polariton resonance (LSPR) of noble metal nanoparticles (NPs) is widely exploited for enhanced optical spectroscopies of molecules, ${ }^{1}$ nonlinear optics, ${ }^{2,3}$ photothermal therapy, ${ }^{4}$ photovoltaics, ${ }^{5,6}$ or more recently in plasmoelectronics ${ }^{7,8}$ and photocatalysis. $^{9-11}$ Hence, noble metal nanostructures embedded in dielectric films hold a great potential for the development of electronic/plasmonic devices. These systems allow the localization, the enhancement, and the manipulation of electromagnetic fields and charge transfers, resulting in a range of unique optical phenomena. ${ }^{12}$ The most efficient metals for electromagnetic field enhancement at optical frequencies are silver (Ag), gold, or copper, among which silver exhibits the strongest LSPR because of lower interference between intraband and interband electronic transitions. ${ }^{13}$ In the case of $\mathrm{Ag}$, embedding of the NPs in a transparent dielectric matrix avoids their alteration (oxidation and sulfuration) but also their dissemination, while preserving their plasmonic properties and keeping a flat and reusable surface. ${ }^{14}$ The LSPR frequency and intensity depend not only on the noble metal NP material, shape, and size but also on its environment, i.e., of the embedding matrix. Despite their importance, the effects caused by capping of dielectric materials (oxides or nitrides) on the structure (morphology and composition) and optical response of noble metal NPs are poorly studied. For instance, a local modification of the environment (i.e., when the noble metal nano-object is lying on a dielectric surface) has a global effect on the energy and symmetry of the LSP modes. ${ }^{15,16}$ In particular, there are several advantages to use silicon nitride $\left(\mathrm{SiN}_{\mathrm{x}}\right)$ as an embedding matrix: this material, widely used as anti-reflective layer in solar cell technology, can redshift the

\footnotetext{
a)bonafos@cemes.fr

${ }^{b)}$ Present address: V. Lashkaryov Institute of Semiconductor Physics, National Academy of Sciences of Ukraine, 45 Pr. Nauky, 03028 Kyiv, Ukraine.
}

LSPR of embedded NPs from UV to the visible range, thanks to its higher refractive index compared to silica $\left(\mathrm{SiO}_{2}\right)$. At the same time, the confinement of the electromagnetic energy at the vicinity of the NPs is enhanced in this high index material. Metallic nanoparticles embedded in $\mathrm{Si}_{3} \mathrm{~N}_{4}$ layers are also studied for their ultrafast response and optical nonlinearities, ${ }^{3,17}$ revealing their great potential value in the development of electronic and optical nanodevices. In addition, the use of nanostructured dielectric layers fabricated on thin film solar cells have been recently demonstrated to provide simultaneously both antireflection functionality and light trapping increase. ${ }^{18}$

Recently, a strategy to design and fabricate hybrid metallic-dielectric substrates for optical spectroscopy and imaging has been proposed. ${ }^{19}$ Different architectures consisting of three-dimensional (3D) patterns of metallic nanoparticles embedded in dielectric layers are conceived to simultaneously exploit the optical interference phenomenon in stratified media and LSPR of metal nanoparticles. These architectures are fabricated by low energy ion beam synthesis (LE-IBS) and consist of a delta-layer of Ag-NPs with controlled size, density, and location, and embedded in silica/silicon thin films. ${ }^{19,20}$

In this letter, we show how using the same concept but a different dielectric matrix, i.e., silicon nitride, we drastically improved the optical properties of the dielectric/Ag-NPs composite substrate. In particular, using a higher dielectric constant allows the plasmon resonance to be enhanced and shifted from near-UV $(3.1 \mathrm{eV})$ to the visible mid-range $(2.6 \mathrm{eV})$. By coupling this refractive index effect to the relevant choice of dielectric thickness for an optimum antireflective effect, plasmon-optical interference can be obtained. We will also show that the use of a silicon nitride matrix, which is a diffusion barrier for $\mathrm{Ag},{ }^{21}$ allows for the introduction of a higher amount of $\mathrm{Ag}$ in the matrix, comparing to $\mathrm{SiO}_{2}$. 
Unexpectedly, the high density of Ag-NPs, which hence nucleates close to the free surface, leads in particular, implantation conditions to in-plane self-organization effects. The possible driving force for this process will be discussed.

$179+/-9 \mathrm{~nm}$ thick $\mathrm{SiN}_{\mathrm{x}}$ layers were grown on $\mathrm{Si}$ substrates at $500^{\circ} \mathrm{C}$ by RF reactive magnetron sputtering of Si target in $\mathrm{N}_{2}$-rich plasma. The refractive index, measured by ellipsometry, is $n=2.06$ at $532 \mathrm{~nm}(2.3 \mathrm{eV})$. More details on the fabrication process can be found elsewhere. ${ }^{22}$ Low energy $\mathrm{Ag}^{+}$ions were implanted in these layers by means of a Varian $200 \mathrm{~A} 2$ implanter at $8 \mathrm{keV}$ for $9 \times 10^{15} \mathrm{~cm}^{-2}$ and at $20 \mathrm{keV}$ for 3 ion doses of $1.5 \times 10^{16} \mathrm{~cm}^{-2}, 3 \times 10^{16} \mathrm{~cm}^{-2}$, and $4.5 \times$ $10^{16} \mathrm{~cm}^{-2}$. The ion current, which has a great influence on silver diffusion, has been kept constant at $5 \mu \mathrm{A} \cdot{ }^{19,20}$ To predict the concentration of implanted ions, we performed TRIDYN simulations, which simulates the dynamic change of thickness (due to sputtering) and composition of the target during highdose ion implantation. ${ }^{23}$ Cross-sectional (XS) and plan-view (PV) specimens were prepared for transmission electron microscopy (TEM) examination by the standard procedure involving grinding, dimpling, and $\mathrm{Ar}^{+}$ion beam thinning until electron transparency. Cooled ion milling has been used in order to avoid $\mathrm{Ag}$ diffusion and structure modification during sample preparation. A FEI Tecnai microscope equipped with a field emission gun and a spherical aberration corrector and operating at $200 \mathrm{keV}$ was used for imaging. Reflectance measurements were performed in quasinormal incidence $\left(6^{\circ}\right)$ by using a Varian Cary 5000 spectrophotometer. To record the low-frequency Raman scattering originating from the Ag nanocrystals a T64000 Horiba-Jobin Yvon triple-monochromator was used. Spectra were recorded with the $531 \mathrm{~nm}$ line of a krypton laser, a power of $1.2 \mathrm{~mW}$ focused by a $12 \mathrm{~mm}$ focal length lens and collected by a 0.55 numerical aperture longworking distance objective.

To get more accurate information at the nanoscale on the metallic particles, we have first performed simulations of the reflectance and of the extinction efficiency using the classical Maxwell Garnett theory. Our approach is reported in details in Ref. 19. By changing the embedding medium from $\mathrm{SiO}_{2}\left(\mathrm{n}_{\mathrm{SiO}_{2}}\right.$, visible $\left.=1.47\right)$ to $\mathrm{SiN}_{\mathrm{x}}\left(\mathrm{n}_{\mathrm{SiN}_{\mathrm{x}}}\right.$, visible $\left.=2.06\right)$, a strong enhancement of the LSPR and its tuning in the middle of the visible were obtained. The LSPR of Ag-NPs shifts from the near UV range $(\cong 400 \mathrm{~nm}, 3.1 \mathrm{eV})$ to the visible range ( $\cong 475 \mathrm{~nm}, 2.6 \mathrm{eV})$ as demonstrated by the theoretical simulations shown in Fig. 1. In this figure, the extinction coefficient has been calculated for a spherical Ag-NP with a diameter $D=3 \mathrm{~nm}$. Owing to the fact that the higher the refractive index, the better the electromagnetic energy confinement, the quality factor is doubled when changing $\mathrm{SiO}_{2}$ to $\mathrm{SiN}_{\mathrm{x}}$. In addition, engineering the architecture of the stacking layer is a key to take simultaneously advantage of spectrally and spatially LSPR but also of optical amplification. ${ }^{19}$ By choosing an appropriate thickness for $\mathrm{SiN}_{\mathrm{x}}$, one can tune the spectral positions of one of the antireflective minima and LSPR, as shown in Fig. 1. More specifically, it is of importance to note that a quasi-perfect anti-reflectance $(\mathrm{R} \approx 0.1 \%)$ is expected with a simple bilayer system because phase and amplitude matching can be simultaneously fulfilled. The anti-reflectance condition is modified under oblique incidence. However, when changing the incidence angle from $0^{\circ}$

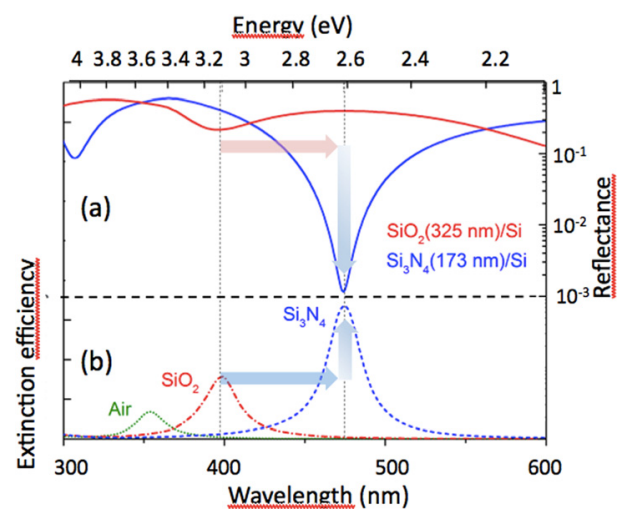

FIG. 1. Simulations of (a) the reflectance using the classical Maxwell Garnett theory for different embedding media (air, $\mathrm{SiO}_{2}$, and $\mathrm{Si}_{3} \mathrm{~N}_{4}$ ) and (b) extinction coefficient of $3 \mathrm{~nm}$ diameter Ag-NPs embedded in these different matrices. The optical constants of $\mathrm{SiO}_{2}$ and $\mathrm{Si}_{3} \mathrm{~N}_{4}$ have been taken from the literature. ${ }^{24}$ The red arrow shows the effect of changing the thickness of the matrix, and the blue one shows the effect of changing the embedding medium.

to $45^{\circ}$, the wavelength of the dip in the visible range displays a blue shift around $20 \mathrm{~nm}$ and the minimum reflectance value only increases from $0.2 \%$ to $1.7 \%$. Thus, the $\mathrm{SiN}_{\mathrm{x}} / \mathrm{Si}$ heterostructure is well adapted to manage amplifying processes in the visible range by simultaneously exploiting the resulting optical interference phenomenon and LSPR.

The reflectance spectra for the three samples implanted at $20 \mathrm{keV}$ for increasing doses are shown in Fig. 2(a) for nonimplanted (black line) and implanted (red, blue, and green lines) samples. The reflectance value is indeed nearly zero for specific energies of the incident photons allowing an optimal coupling with the Ag-NPs located close to the surface. The interference dips around 2.5 and $3.9 \mathrm{eV}$ attributed to antireflective effects display a blue-shift with respect to the unimplanted sample, which increases with the dose. This shift is indicative of an optical path shortening in the dielectric layer, as already observed when implanting $\mathrm{Ag}^{+}$in silica. ${ }^{19}$ This is an evidence of a decrease in thickness of the $\operatorname{SiN}_{\mathrm{x}}$ layer due the surface recession by ion etching during the implantation process, as it will be confirmed later by the TEM observations. In Fig. 2(b) is reported the differential reflectance $\Delta R=R-R_{0}$ with $R$ the reflectance of an implanted zone and $R_{0}$ the one of a non-implanted zone. This experimental curve is well accounted for by theoretical one calculated with our model. ${ }^{19}$ From this comparison, we can thus deduce structural parameters characteristics of the NP population (average diameter and implanted dose). Specifically, the average diameter of the Ag-NPs deduced from the best fit of the experimental reflectance for the sample with a dose of $3 \times$ $10^{16} \mathrm{~cm}^{-2}$ is $4.4 \mathrm{~nm}$.

The Bright Field XS-TEM image of the layer implanted with the intermediate dose $\left(3 \times 10^{16}\right.$ ions $\left.\mathrm{cm}^{-2}\right)$ is shown in Fig. 3(a). The whole $\mathrm{SiN}_{\mathrm{x}}$ layer is $167 \mathrm{~nm}$ thick, i.e., thinner than the non-implanted layer $(179 \mathrm{~nm})$, due to sputtering effects during implantation as shown in a previous work for Ag implanted silica matrices. ${ }^{20}$ No porosity can be observed, testifying of the good quality of the layer. We observe the formation of a plane of Ag-NPs that are separated by only $2 \mathrm{~nm}$ from the $\mathrm{SiN}_{\mathrm{x}}$ free surface, with an average diameter of $4.4+/-0.2 \mathrm{~nm}$. Under this 2D array of "big" NPs, we can find a $10 \mathrm{~nm}$ thick band of smaller Ag-NPs (with size of 

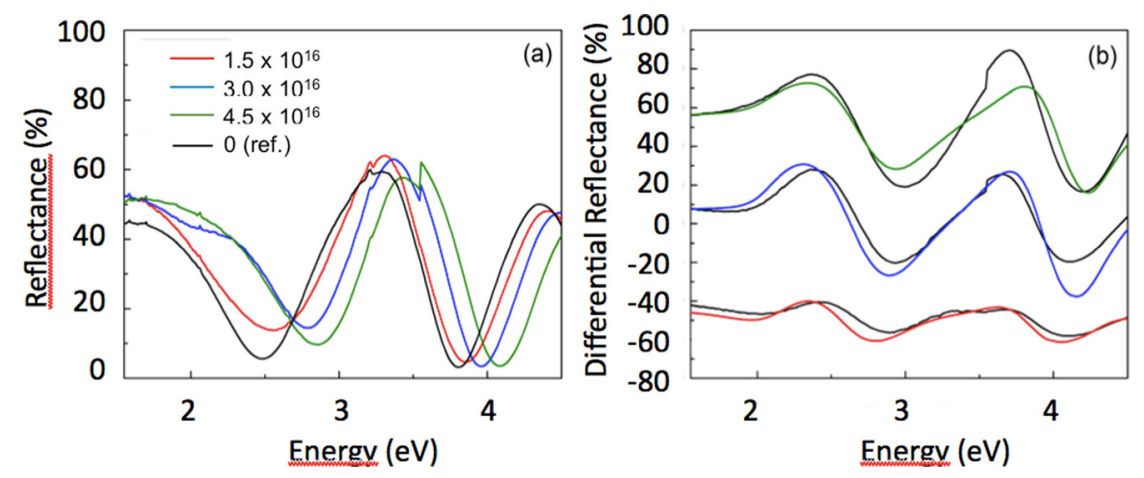

FIG. 2. (a) Experimental reflectance spectra for non-implanted (black line) and implanted samples at $20 \mathrm{keV}$ for 3 ion doses of $1.5 \times 10^{16} \mathrm{~cm}^{-2}, 3 \times$ $10^{16} \mathrm{~cm}^{-2}$, and $4.5 \times 10^{16} \mathrm{~cm}^{-2}$; (b) differential reflectance (experiment in black) compared to Maxwell Garnett simulations (the spectra for the lower and higher dose have been shifted from $50 \%$ for clarity).
$2 \mathrm{~nm}$ ) in perfect agreement with the value deduced from reflectance measurements. High Resolution Transmission Electron Microscopy (HRTEM) image of an isolated particle (see inset of Fig. 3) shows interplanar distances of $2.3 \AA$, characteristic of $\mathrm{Ag}$ (111) planes, confirming the presence of pure Ag nanocrystals. The nucleation of these crystalline AgNPs occurs during the implantation process without the need of any annealing step as in the case of $\mathrm{Ag}^{+}$implantation in silica. ${ }^{19,20,25,26}$ This happens because $\mathrm{Ag}$ concentration is higher than the solubility threshold nearly room temperature and because of $\mathrm{Ag}$ diffusion is promoted by the long duration of the implantation process (more than $20 \mathrm{~h}$ ). We obtain a rather good agreement between the widths of the implanted profile as calculated by TRIDYN (not shown) and of the observed NPs layer. The asymmetry of the structure, with the formation of the biggest NPs close to the surface and small NPs only below this plane could be attributed to two concomitant phenomena: Ag exo-diffusion towards the surface as observed in $\mathrm{Ag}^{+}$implanted silica and surface recession due to ion sputtering. ${ }^{20}$ Whatever the implantation conditions, this band of small $(2 \mathrm{~nm})$ NPs is always observed.

Figure 4 shows the associated Bright Field PV-TEM observation of this implanted sample. The implanted dose, i.e., the number of atoms stored within the Ag-NPs by surface unit, measured on the PV images is $10^{16} \mathrm{~cm}^{-2}$. This value is one third of the nominal dose, in perfect agreement with reflectance measurements (not shown). The ratio between the implanted dose and the nominal dose $(>30 \%)$ is nevertheless larger than the one obtained by implanting $\mathrm{Ag}^{+}$in $\mathrm{SiO}_{2}$ for this range of implantation energy and dose (around 20\% only). The dose saturation effect, already observed when implanting $\mathrm{Ag}^{+}$in silica and due to both sputtering and diffusion effects, ${ }^{20}$ seems to be reduced in $\mathrm{SiN}_{\mathrm{x}}$ probably due to the lowest diffusion of $\mathrm{Ag}$ in such a host matrix. ${ }^{21}$ When increasing the implanted dose, the average diameter of the big NPs (located in the plane close to the surface) first increases from 2.1 to $4.4 \mathrm{~nm}$ (see Figs. 3(b) and 3(c)) and then decreases to $3.4 \mathrm{~nm}$ (Fig. 3(d)) as a consequence of sputtering effects. ${ }^{20}$

Surprisingly, a self-organization following centeredhexagons is observed at short ranges in thin regions, where only the plane of "big" nanocrystals (NCs) is projected (Fig. 4(b)). The cross-correlation function of this image (Fig. 4(c)) confirms this observation, with two characteristic distances measured in the profile (Fig. 4(d)): $4 \mathrm{~nm}$ (the average NCs diameter) and $10 \mathrm{~nm}$ (the average distance between the NCs). The other samples implanted with the different dose and/or energy do not show any particular organization: the Ag-NPs are randomly dispersed in the matrix as in the case of Ag-NPs embedded in $\mathrm{SiO}_{2}$ shown in Refs. 19, 20, and 27. This self-organization is accompanied by a sharpening of the

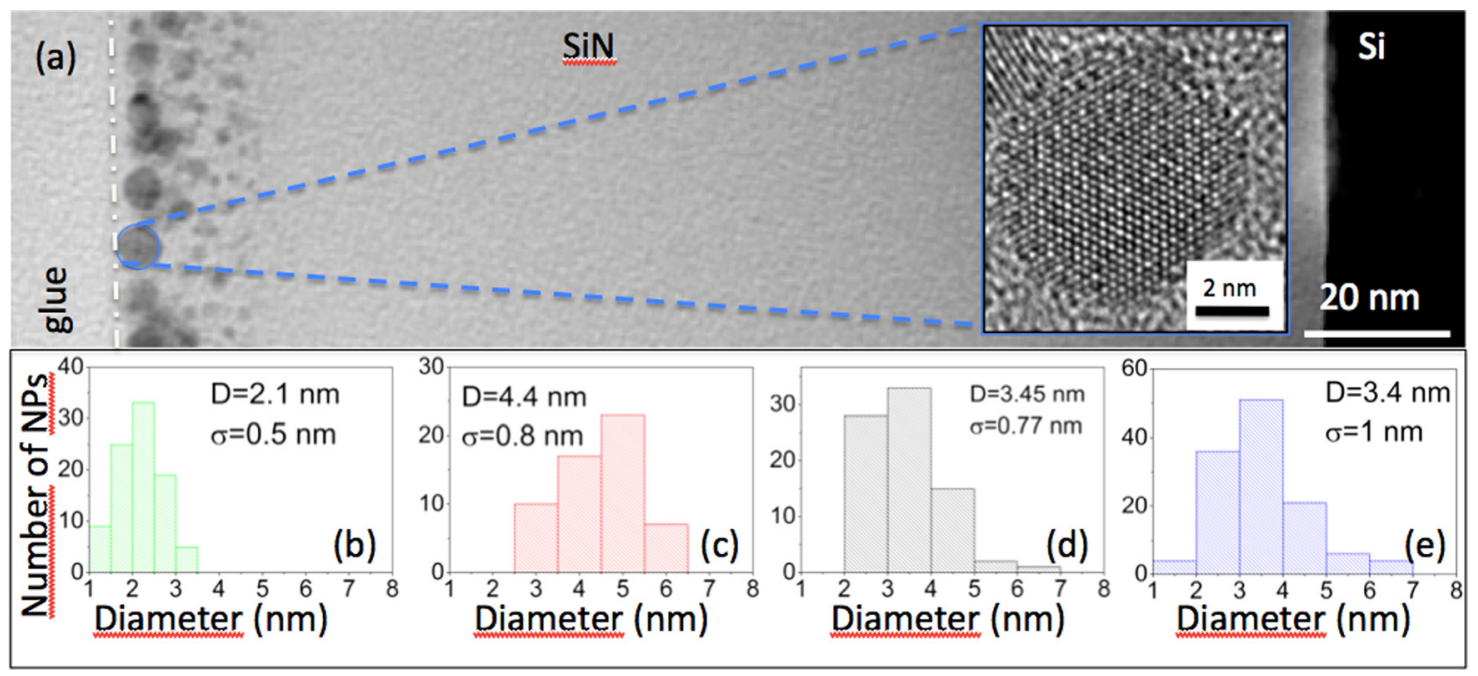

FIG. 3. (a) Bright Field XS-TEM image of the layer implanted with the intermediate dose $\left(3 \times 10^{16} \mathrm{~cm}^{-2}\right)$. In inset is shown an HREM image of an isolated Ag nanocrystal. Size-distributions of the samples implanted at $20 \mathrm{keV}$ for doses (b) $1.5 \times 10^{16} \mathrm{~cm}^{-2}$, (c) $3 \times 10^{16} \mathrm{~cm}^{-2}$, and (d) $4.5 \times 10^{16} \mathrm{~cm}^{-2}$. The sizehistogram for the sample implanted at $8 \mathrm{keV}$ for $9 \times 10^{15} \mathrm{~cm}^{-2}$ is also added in (e). Only the first plane containing the biggest NPs has been taken into account in the size measurement. 

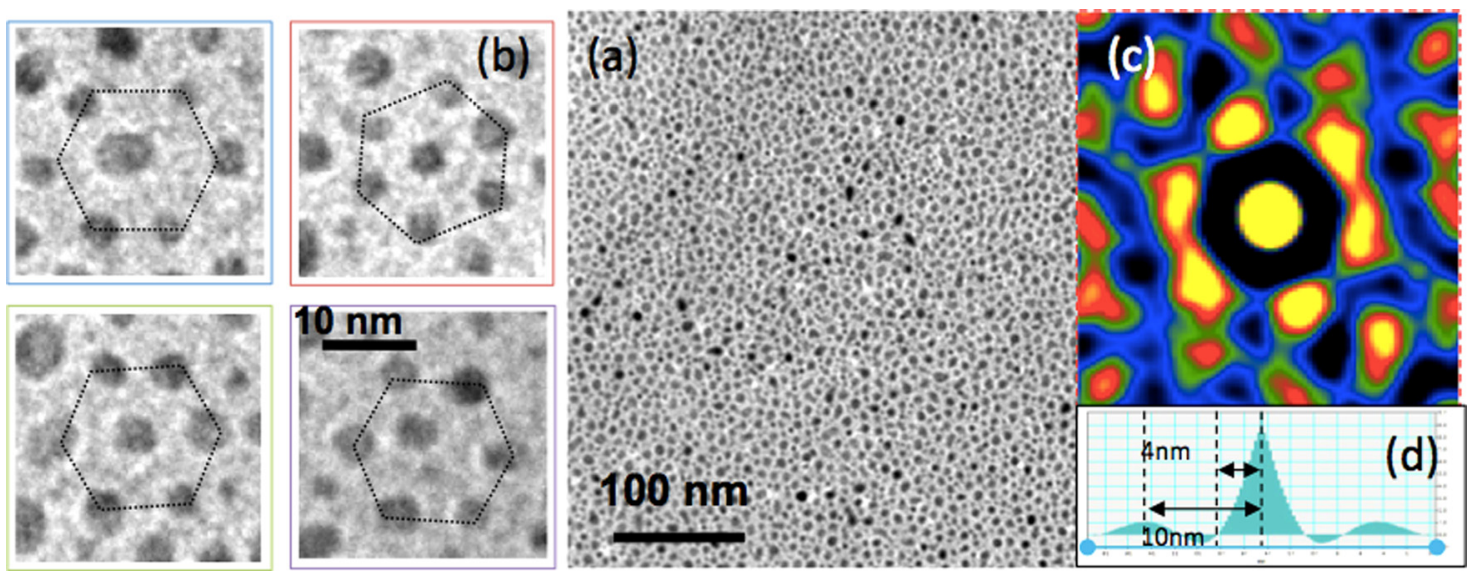

FIG. 4. (a) Bright field low magnification TEM observation in plan-view of the sample implanted with the intermediate dose; (b) zoom of the Ag-NPs hexagonal arrangements; (c) cross-correlation function of the image, and (d) profile on the cross-correlation image, showing the characteristics distances.

size-distribution: the ratio between the standard deviation and the mean diameter is largely reduced when going from disordered to the ordered array of NPs. This sharpening is also confirmed by the value of the cut-off diameter of the size-histogram, i.e., the ratio between the largest diameter and the average one. This cut-off radius is 1.3 only for the self-organised NPs (Fig. 3(b)); meanwhile, it ranges in between 1.5 and 2 for disordered assemblies (as the ones shown in Figs. 3(a), 3(c), 3(d), and 3(e) or the ones synthesized in $\mathrm{SiO}_{2}$ shown in Refs. 19, 20, and 27) that encompass a classical Ostwald Ripening competitive growth. ${ }^{28}$

The dynamical response of a material is highly correlated to its structure. In that sense, Raman spectroscopy has been efficiently used to analyze structuration of metal-dielectric composite layers at the nanoscale or atomic scale. ${ }^{19,27} \mathrm{We}$ have thus recorded Raman spectra on $\mathrm{SiN}_{\mathrm{x}} / \mathrm{Si}$ bilayers containing Ag-NCs. Owing to the fact that (i) the electromagnetic field is maximum at the vicinity of the free surface in an antireflective system ${ }^{19}$ and (ii) one takes benefit of surface enhanced Raman Scattering (i.e., SERS) effects using the $531 \mathrm{~nm}(2.34 \mathrm{eV}) \mathrm{Kr}^{+}$laser line as excitation, the signature of a single plane of $\mathrm{Ag}-\mathrm{NCs}$ is easily detected. In Fig. 5 are reported the Raman spectra of two samples, a "disordered" one with broad size and inter-distance distributions and the other presenting self-organization effects, as previously observed by TEM. These spectra are compared to those of non-implanted zones and recorded on both Stokes and antiStokes range in order to ensure that the signal strictly originates from inelastic processes in Ag-NCs assemblies. Indeed, the spectra of the non-implanted samples only contain the Brillouin peaks of the Si substrate, and all the spectra are symmetric with regards to the Rayleigh line, testifying they results from purely Raman processes. To account for the whole spectrum shape, one must remain in mind that the Raman scattering spectral response is proportional to the space-time Fourier components of the "dynamic" auto-correlation functions of the dielectric tensor fluctuations. The frequency dynamical response is thus advantageously compared to the radial dependence of the Fourier transform of the "static" autocorrelation function (reported in the insets of Fig. 5). The absence of any structuration in the disordered sample strikingly contrasts with the modulation observed in the responses of the self-organized sample. In this low frequency $(\mathrm{THz})$ range, dynamical fluctuations come from atomic vibrations. ${ }^{27}$ The frequency shift of the features scales with the inverse distance, explaining thus some similarity between static and dynamic responses in Fig. 5. In the Raman response, the selforganization effect (that is correlated to a narrowing of the size distribution, see Fig. 3(b) and 3(e)) is evidenced by a supplementary and well-defined low frequency structure located at $11.5 \pm 0.5 \mathrm{~cm}^{-1}(\sim 0.30 \mathrm{THz})$. We ascribed this structure to the fundamental quadrupolar Lamb mode of the Ag-NPs. For a spherical Ag nanocrystal of diameter $D$ embedded in $\mathrm{SiO}_{2}$ or $\mathrm{Al}_{2} \mathrm{O}_{3}$ it has been shown theoretically and well verified experimentally ${ }^{29}$ that $\omega\left(\mathrm{cm}^{-1}\right) \approx 47 / \mathrm{D}(\mathrm{nm})$. Using this relation (that should not be notably modified for $\mathrm{SiN}_{\mathrm{x}}$ ), one deduces that the NCs population presents a rather low size dispersion around an average diameter $D=4.1 \pm 0.2 \mathrm{~nm}$, in good agreement with TEM observations and reflectance. The expected 2D hexagonal supra-crystallinity effect is not

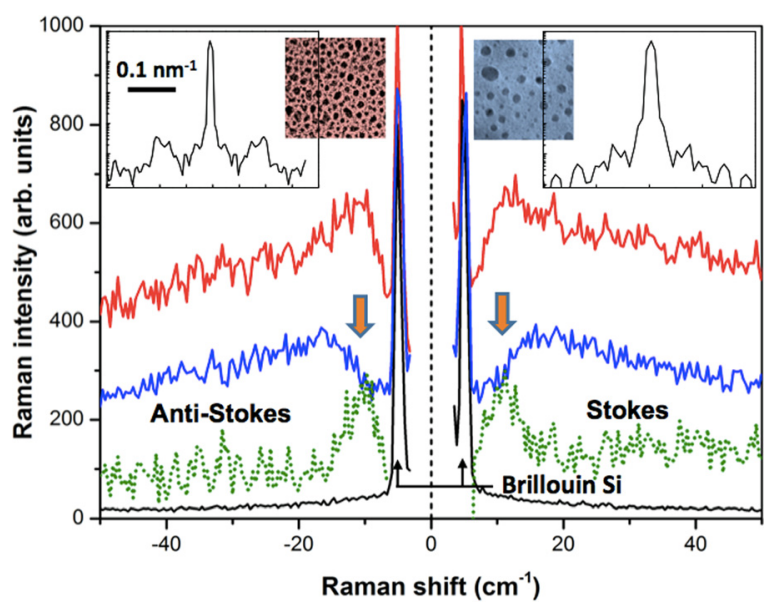

FIG. 5. Raman spectra of two samples: (a) a disordered one (blue curve), typically the one implanted at $8 \mathrm{keV}$ and $0.9 \times 10^{16} \mathrm{~cm}^{-2}$, showing a broad size and inter-distance distributions and (b) the one implanted with the intermediate dose (red curve) presenting self-organization effects. The difference between spectra (a) and (b) is reported in green dotted lines to exemplify the superstructure (see arrows) at low frequency near $11 \mathrm{~cm}^{-1}$. In inset, radial dependence of the Fourier transform of the "static" auto-correlation functions for the two PV-TEM images associated with each sample (the superstructure is indicated by arrows). 
observable here due to the frequency cut-off near the elastic line. Nevertheless, one may argue here that 2D selforganization of embedded metallic NCs may be exploited for modulating the acoustic response in the sub-THz regime.

Self-assembled nanocrystals in 3D superlattices, called supracrystals, have been obtained with deposits from colloidal solution of metal nanocrystals, and the resulting optical and vibrational properties intensively studied. ${ }^{30}$ Selforganization of embedded NCs elaborated by ion implantation has already been predicted but usually manifests itself in the form of layering. In-depth stratification is indeed predicted in finite precipitate systems during annealing and is caused by Ostwald ripening. ${ }^{31}$ The onset of the layer formation is shown to be triggered by the inhomogeneity of the impurity concentration profile near a boundary of a precipitate system and not by spatially uniform nonlocal fluctuation instability of precipitate parameters. Hence, the formation of multilayered structures from initially uniform precipitate distributions is predicted to occur both in finite precipitate ensembles $^{32}$ and in layers, i.e., in systems finite in one dimension only. ${ }^{33-35}$ Nevertheless, the self-organization of NCs that we observe here takes place in the plane and not in depth and therefore cannot be attributed to this process. Sharp size-distribution and homogeneous distances between the NCs, as observed here, could be the result of metastable processes of ultradense arrays of precipitates as predicted in Ref. 36. Short-range elastic interactions between coherently strained precipitates (in Ref. 36 conical islands) can stabilize dense arrays against ripening leading to a finite region of metastability. Our observations could be an experimental evidence of this type of metastable coarsening regime for spherical precipitates. It is important to notice that this selforganization has been observed only in this particular energy and dose condition. Other implantation conditions for $\mathrm{Ag}^{+}$ in $\mathrm{SiN}_{\mathrm{x}}$ have been tested without giving rise to such process. Further experiments will be carried out in order to measure stress on one side in the whole $\mathrm{SiN}_{\mathrm{x}}$ layer by using the wafer curvature technique and on the other side in individual NPs by using TEM based techniques.

In conclusion, we have shown that changing silica by silicon nitride based layers with a dielectric constant higher than silica allows the plasmon resonance of embedded AgNPs to be enhanced and shifted from UV to the visible range. By coupling this refractive index effect to the relevant choice of dielectric thickness for an optimum antireflective effect, a plasmon optical interference effect can be obtained. The $\mathrm{SiN}_{\mathrm{x}}$ matrix being a diffusion barrier for $\mathrm{Ag}$ allows the introduction of a higher amount of $\mathrm{Ag}$ in the matrix, comparing to $\mathrm{SiO}_{2}$. Hence, the formation of a high density of Ag-NPs during the implantation process leads under particular implantation conditions to an in-plane self-organization effect. This process could be the result of metastable coarsening regime for spherical precipitates, implying very dense arrays of NPs and with driving force short-range elastic interactions between strained precipitates. The fabrication of such embedded 2D super-crystal should be of great interest for modulating acoustic or thermodynamic properties in the $\mathrm{THz}$ regime. At last, these nanostructured dielectric layers are good candidates for advanced antireflection coatings for thin film solar cell applications.
M.B. thanks the University of Toulouse and Région Midi-Pyrénées for financial support. Part of this work was supported by Programme Investissements d'Avenir under the program ANR-11-IDEX-0002-02, reference ANR-10LABX-0037-NEXT.3850.

${ }^{1}$ S. Nie, Science 275, 1102 (1997).

${ }^{2}$ A. Traverse, C. Humbert, C. Six, A. Gayral, and B. Busson, EPL 83, 64004 (2008).

${ }^{3}$ J. Toudert, H. Fernandez, D. Babonneau, S. Camelio, T. Girardeau, and J. Solis, Nanotechnology 20, 475705 (2009).

${ }^{4}$ G. Baffou and R. Quidant, Laser Photon. Rev. 7, 171 (2013).

${ }^{5}$ H. A. Atwater and A. Polman, Nat. Mater. 9, 205 (2010).

${ }^{6}$ S. Linic, P. Christopher, and D. B. Ingram, Nat. Mater. 10, 911 (2011).

${ }^{7}$ S. C. Warren, D. A. Walker, and B. A. Grzybowski, Langmuir 28, 9093 (2012).

${ }^{8}$ P. Spinelli and A. Polman, Opt. Express 20, A641 (2012).

${ }^{9}$ X. Zhang, Y. L. Chen, R.-S. Liu, and D. P. Tsai, Rep. Prog. Phys. 76, 046401 (2013).

${ }^{10}$ G. Prieto, J. Zecevic, H. Friedrich, K. P. de Jong, and P. E. de Jongh, Nat. Mater. 12, 34 (2013).

${ }^{11}$ S. Mukherjee, F. Libisch, N. Large, O. Neumann, L. V. Brown, J. Cheng, J. B. Lassiter, E. A. Carter, P. Nordlander, and N. J. Halas, Nano Lett. 13, 240 (2013).

${ }^{12}$ G. V. Hartland, Chem. Rev. 111, 3858 (2011).

${ }^{13}$ U. Kreibig and M. Vollmer, Optical Properties of Metal Clusters (Springer-Verlag, Berlin, Heidelberg, 1995).

${ }^{14}$ P. Benzo, L. Cattaneo, C. Farcau, A. Andreozzi, M. Perego, G. Benassayag, B. Pecassou, R. Carles, and C. Bonafos, J. Appl. Phys. 109, 103524 (2011).

${ }^{15}$ S. Zhang, K. Bao, N. J. Halas, H. Xu, and P. Nordlander, Nano Lett. 11, $1657-1663$ (2011).

${ }^{16}$ S. Mazzucco, N. Geuquet, J. Ye, O. Stephan, W. Van Roy, P. Van Dorpe, L. Henrard, and M. Kociak, Nano Lett. 12, 1288-1294 (2012).

${ }^{17}$ Z. Dong, G. You, P. Zhou, C.-F. Zhang, K. Liu, Y. Yan, and S. Qian, J. Phys. D: Appl. Phys. 39, 4766-4770 (2006).

${ }^{18}$ X. H. Li, P. C. Li, D. Z. Hu, D. M. Schaadt, and E. T. Yu, J. Appl. Phys. 114, 044310 (2013).

${ }^{19}$ R. Carles, C. Farcau, C. Bonafos, G. Benassayag, M. Bayle, P. Benzo, J. Groenen, and A. Zwick, ACS Nano 5, 8774 (2011).

${ }^{20}$ P. Benzo, C. Bonafos, M. Bayle, R. Carles, L. Cattaneo, C. Farcau, G. Benassayag, B. Pécassou, and D. Muller, J. Appl. Phys. 113, 193505 (2013).

${ }^{21} \mathrm{G}$. Baret, "Use of a nitride barrier for avoiding silver migration into glass," U.S. patent 5,968,637 A (19 October 1999).

${ }^{22}$ O. Debieu, R. P. Nalini, J. Cardin, X. Portier, J. Perrière, and F. Gourbilleau, Nanoscale Res. Lett. 8, 31 (2013).

${ }^{23}$ W. Möller and W. Eckstein, Nucl. Instrum. Methods Phys. Res. B 2, 814 (1984).

${ }^{24}$ M. N. Polyanskiy, Refractive Index Database, http://refractiveindex.info (2013).

${ }^{25}$ W. M. Tsang, V. Stolojan, C. Giusca, H. P. Poa, B. Sealy, S. R. P. Silva, and S. P. Wong, J. Vac. Sci. Technol., B 24, 958 (2006).

${ }^{26}$ Z. Liu, H. Wang, and H. Li, Appl. Phys. Lett. 72, 1823 (1998).

${ }^{27}$ M. Bayle, P. Benzo, N. Combe, C. Gatel, C. Bonafos, G. Benassayag, and R. Carles, Phys. Rev. B 89, 195402 (2014).

${ }^{28}$ I. M. Lifshitz and V. V. Slyosov, J. Phys. Chem. Solids 19, 35 (1961).

${ }^{29}$ B. Palpant, H. Portales, L. Saviot, J. Lerme, B. Prevel, M. Pellarin, E. Duval, A. Perez, and M. Broyer, Phys. Rev. B 60, 17107-17111 (1999).

${ }^{30}$ N. Goubet, C. Yan, D. Polli, H. Portales, I. Arfaoui, G. Cerullo, and M. P. Pileni, Nano Lett. 13, 504 (2013).

${ }^{31}$ V. A. Borodin, K. H. Heinig, and S. Reiss, Phys. Rev. B 56, 5332 (1997).

${ }^{32}$ S. Reiss and K. H. Heinig, Nucl. Instrum. Methods Phys. Res. B 84, 229 (1994).

${ }^{33}$ S. Feeney, L. Schmidt, P. Strickholm, J. Chadam, and P. Ortoleva, J. Chem. Phys. 78, 1293 (1983).

${ }^{34}$ G. Venzl, J. Chem. Phys. 85, 1996 (1986)

${ }^{35}$ S. Reiss and K. H. Heinig, Nucl. Instrum. Methods Phys. Res. B 112, 223 (1996).

${ }^{36}$ V. A. Shchukin, D. Bimberg, T. P. Munt, and D. E. Jesson, Phys. Rev. Lett. 90, 076102 (2003). 